\title{
Dietary arginine silicate inositol complex inhibits periodontal tissue loss in rats with ligature- induced periodontitis
}

This article was published in the following Dove Press journal:

Drug Design, Development and Therapy

I5 November 2016

Number of times this article has been viewed

\author{
Serkan Dundar' \\ Abubekir Eltas ${ }^{2}$ \\ Sema S Hakki ${ }^{3}$ \\ Siddık Malkoc ${ }^{4}$ \\ M Ozay Uslu² \\ Mehmet Tuzcu ${ }^{5}$ \\ James Komorowski ${ }^{6}$ \\ I Hanifi Ozercan ${ }^{7}$ \\ Fatih Akdemir ${ }^{8}$ \\ Kazim Sahin ${ }^{9}$ \\ 'Department of Periodontology, \\ Faculty of Dentistry, Firat University, \\ Elazig, ${ }^{2}$ Department of Periodontology, \\ Faculty of Dentistry, Inonu \\ University, Malatya, ${ }^{3}$ Department \\ of Periodontology, Faculty of \\ Dentistry, Selcuk University, Konya, \\ ${ }^{4}$ Department of Orthodontics, Faculty \\ of Dentistry, Inonu University, Malatya, \\ ${ }^{5}$ Department of Biology, Faculty \\ of Science, Firat University, Elazig, \\ Turkey; ${ }^{6}$ Research \& Development, \\ Nutrition 2I Inc., Purchase, NY, USA; \\ ${ }^{7}$ Department of Pathology, Faculty \\ of Medicine, ${ }^{8}$ Department of Animal \\ Nutrition, Faculty of Fisheries, Inonu \\ University, Malatya, ${ }^{9}$ Department \\ of Animal Nutrition, Faculty of \\ Veterinary Medicine, Firat University, \\ Elazig, Turkey
}

Correspondence: Kazim Sahin

Department of Animal Nutrition, Faculty of Veterinary Medicine, Firat University,

Elazig 23119, Turkey

Tel +90 5327473506

Email nsahinkm@yahoo.com
Abstract: The purpose of this study was to induce experimental periodontitis in rats previously fed diets containing arginine silicate inositol (ASI) complex and examine the biochemical, immunological, and radiological effects. Fifty two 8-week-old female Sprague Dawley rats were equally divided into four groups. The control group included those fed a standard rat diet with no operation performed during the experiment. The periodontitis, ASI I, and ASI II groups were subjected to experimental periodontitis induction for 11 days after being fed a standard rat diet alone, a diet containing $1.81 \mathrm{~g} / \mathrm{kg}$ ASI complex, or a diet containing $3.62 \mathrm{~g} / \mathrm{kg}$ ASI complex, respectively, for 8 weeks. Throughout the 11-day duration of periodontitis induction, all rats were fed standard feed. The rats were euthanized on the eleventh day, and their tissue and blood samples were collected. In the periodontitis group, elevated tissue destruction parameters and reduced tissue formation parameters were found, as compared to the ASI groups. Levels of enzymes, cytokines, and mediators associated with periodontal tissue destruction were lower in rats fed a diet containing ASI complex after experimental periodontitis. These results indicate that ASI complex could be an alternative agent for host modulation.

Keywords: arginine silicate inositol complex, experimental periodontitis, host modulation, micro-computed tomography, periodontal infection

\section{Introduction}

Periodontitis is a destructive, inflammatory, pathological condition that affects the connective tissue attachment between the alveolar bones of the teeth. ${ }^{1}$ The main etiologic factor of periodontitis is an interaction between periodontal pathogenic bacteria and host tissue response. ${ }^{2-4}$ Since discovering the importance of host immune response in the pathogenesis of periodontal diseases, scientists have investigated host modulation therapy, which alters host tissue response to reduce destructive factors and increase preventive mediators. ${ }^{5,6}$ Various host modulatory agents have been investigated, such as growth factors, tetracycline, antiosteoclastic drugs, antioxidants, enamel matrix proteins, anti-inflammatory drugs, and bone morphogenetic proteins. ${ }^{5,7-10}$ Despite continued research on host modulation therapy, only two agents for host modulation have been approved by the United States Food and Drug Administration (FDA): subantimicrobial-dose tetracycline and enamel matrix protein.

Arginine silicate inositol (ASI) complex is a novel, bioavailable source of arginine and silicon that could serve as an alternative agent for host modulation. ${ }^{11-14}$ The effects of arginine and silicon on bone and connective tissue metabolism in mammals are well documented, and the ASI complex has been shown to benefit bone and vascular health. ${ }^{15}$ Several clinical studies have demonstrated the safety of ASI complex 
components. No adverse effects were observed following administration of arginine. ${ }^{16,17}$ Similarly, no adverse effects were seen following daily administration of $12 \mathrm{~g}$ of inositol for 4 weeks or $45 \mathrm{mg}$ of silicon for 31 days. ${ }^{18,19}$

Recent studies suggest that dietary arginine and silicon play an important role in the development, growth, and remodeling of long bones. ${ }^{20}$ Arginine is involved in collagen synthesis and the production of growth hormones, nitric oxide (NO), and insulin-like growth factor 1 (IGF-1). ${ }^{21-23}$ Arginine administration is clinically suggested for patients recovering from some illnesses and injuries and for conditions related to metabolic disturbance of calcium absorption, such as growth deficiency, dentition and ossification defects, rachitis, osteomalacia, and decalcification. ${ }^{24,25}$ Several roles for silicon have been defined, largely based on animal studies, and its most important function is in the growth and development of bone, cartilage, and connective tissue. ${ }^{26,27}$ There is a direct relationship between silicon and calcium, ${ }^{28}$ and silicon is associated with calcium at an early stage of bone formation. ${ }^{29}$ Additionally, silicon appears to be required for the synthesis of collagen, which is the protein matrix found in connective tissue and is the most abundant protein in the human body. ${ }^{28}$

Although the roles of arginine and silicon in osteoporosis, bone metabolism, connective tissue formation, and collagen metabolism are well documented, information about the effects of ASI complex on host modulation in periodontal diseases is limited. This study aimed to investigate the effects of ASI complex supplementation on periodontal tissues during the periodontitis formation process.

\section{Materials and methods}

\section{Animals and study design}

Fifty-two female Sprague Dawley rats were used in the experiment. Their average body weight was $135 \pm 3 \mathrm{~g}$ at the beginning of the experiment. The animals were kept in temperaturecontrolled cages $\left(\sim 25^{\circ} \mathrm{C}\right)$, exposed to 24 -hour light-dark cycles of equal time, and had free access to food and water. The study protocol and experimental design were approved by the animal ethics committee of Inonu University. All rats received humane care according to the standards defined in the Guide for the Care and Use of Laboratory Animals organized by the Ministry of Agriculture and permitted by the Ethics Committee of the University of Inonu, Malatya, Turkey. Procedures for animal selection, feeding duration, and feeding methods were taken from Proctor et al. ${ }^{12}$ The rats were randomly divided into the following four groups: 1) control group $(n=13)$, fed a basal diet (Table 1) for 8 weeks with no ligature placement; 2) periodontitis group
Table I Composition of basal diet

\begin{tabular}{ll}
\hline Description & Content, \% \\
\hline Wheat & 29.5 \\
Soybean meal & 9.0 \\
Sunflower meal & 36.8 \\
Wheat bran & 9.0 \\
Molasses & 10.0 \\
Limestone & 3.0 \\
Salt & 1.5 \\
DL-methionine & 0.7 \\
Dicalcium phosphate & 0.3 \\
Vitamin-and-mineral premix & 0.2 \\
Analysis & \\
Crude protein & 23.9 \\
Ether extract & 3.1 \\
Crude cellulose & 6.5 \\
Ash & 7.8 \\
Ca & 1.2 \\
P & 0.8 \\
\hline
\end{tabular}

Notes: ${ }^{\text {aThe }}$ vitamin-mineral premix provides the following (per kilogram): alltrans-retinyl acetate, $1.8 \mathrm{mg}$; cholecalciferol, $0.025 \mathrm{mg}$; all-rac- $\alpha$-tocopherol acetate, $12.5 \mathrm{mg}$; menadione (menadione sodium bisulfate), $1.1 \mathrm{mg}$; riboflavin, $4.4 \mathrm{mg}$; thiamine (thiamine mononitrate), $1.1 \mathrm{mg}$; vitamin B6, $2.2 \mathrm{mg}$; niacin, $35 \mathrm{mg}$; Ca-pantothenate, $10 \mathrm{mg}$; vitamin BI2, $0.02 \mathrm{mg}$; folic acid, $0.55 \mathrm{mg}$; D-biotin, $0.1 \mathrm{mg}$. manganese (from manganese oxide), $40 \mathrm{mg}$; iron (from iron sulfate), $12.5 \mathrm{mg}$; zinc (from zinc oxide), $25 \mathrm{mg}$; copper (from copper sulfate), $3.5 \mathrm{mg}$; iodine (from potassium iodide), $0.3 \mathrm{mg}$; selenium (from sodium selenite), $0.15 \mathrm{mg}$; choline chloride, $175 \mathrm{mg}$.

$(\mathrm{n}=13)$, fed a basal diet for 8 weeks prior to 11-day ligature placement; 3) ASI I group $(\mathrm{n}=13)$, fed a supplementation of $1.81 \mathrm{~g} / \mathrm{kg}$ of ASI complex for 8 weeks prior to 11-day ligature placement; and 4) ASI II group ( $n=13)$, fed a supplementation of $3.62 \mathrm{~g} / \mathrm{kg}$ of ASI complex for 8 weeks prior to 11-day ligature placement. General anesthesia was administered using ketamine (40 mg/kg; Pfizer, Istanbul, Turkey). To induce experimental periodontitis, 4-0 silk sutures were placed and knotted submarginally by the same operator around the gingival margin of the right and left mandibular molars of the rats. The sutures were checked after application, and lost or loose sutures were replaced (Figure 1A and B). All rats were fed a standard diet for the 11 days during experimental periodontitis and euthanized by anesthetic overdose (two to three times the anesthetic dosage - of ketamine, administered intramuscularly) on the eleventh day. The mandibles were then separated from muscle and soft tissues.

\section{Western blot analysis}

Gingival tissue samples were collected around the right mandibular first molar tooth and were stored at $-80^{\circ} \mathrm{C}$. Gingival tissues from each group of rats were pooled together for Western blot analysis. Frozen tissue samples were homogenized in phosphate-buffered saline (PBS) with protease inhibitor cocktail, and the protein concentration was quantitated. The gingival tissue samples (20 mg of protein per lane) were 


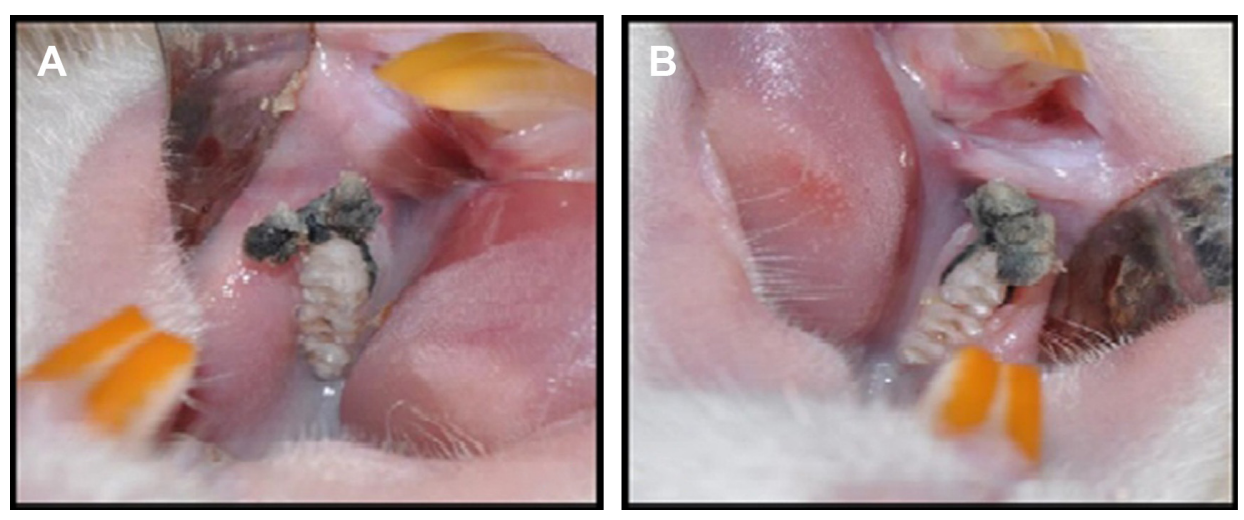

Figure I To induce experimental periodontitis, a 4-0 silk suture was placed and knotted submarginally by the same operator around the gingival margin of the (A) right and (B) left mandibular molars of the rats for II days.

mixed with sample buffer, boiled for 5 minutes, separated by sodium dodecyl sulfate-polyacrylamide $(12 \%)$ gel electrophoresis under denaturing conditions, and electroblotted onto nitrocellulose membranes. The nitrocellulose blots were washed in PBS and blocked with $1 \%$ bovine serum albumin in PBS for 1 hour prior to application of the primary antibody. The primary antibody was diluted 1:1,000 in the same buffer containing $0.05 \%$ Tween 20 . The nitrocellulose membrane was incubated overnight at $4{ }^{\circ} \mathrm{C}$ with protein antibodies. Antibodies against interleukin $1 \beta$ (IL-1 $1 \beta$ ), matrix metalloproteinase 8 (MMP-8), receptor activator of nuclear factor- $\mathrm{KB}$ (RANK) and RANK ligand (RANKL), osteoprotegerin (OPG), myeloperoxidase (MPO), and $\beta$-actin (purchased from Santa Cruz Biotechnology Inc, Dallas, TX, USA) were used to probe the separate membranes. The next day, the immune reaction was continued with secondary goat anti-rabbit horseradish peroxidase-conjugated antibody after washing for 2 hours at room temperature. Specific binding was detected using diaminobenzidine and $\mathrm{H}_{2} \mathrm{O}_{2}$ as substrates. Blotting was performed at least four times to confirm data reproducibility. Protein levels were analyzed densitometrically using an image analysis system.

\section{Radiological analysis}

Micro-computed tomography (micro-CT) analysis was performed to quantify interradicular and interproximal alveolar bone of the right first lower molars. The $\mathrm{X}$-ray source was operated at $100 \mathrm{kV}$ with a $0.5 \mathrm{~mm}$ aluminum filter, and the image size was set to 11 megapixels. A total of $400-450$ reslices with a thickness of 13-14 $\mu \mathrm{m}$ were selected from the top of the cusp down to the alveolar bone in the sagittal plane for each specimen. Samples were scanned with $360^{\circ}$ rotation with a rotation step of $0.40^{\circ}$. Cross-sectional images (compatible with the Digital Imaging and Communication in Medicine standard) were converted to bitmap file format. The crude radiological images were obtained after micro-CT analysis using NRecon software (version 1.6.9.4; SkyScan, Kontich, Belgium). Pollution and image artifacts were eliminated prior to mathematical analysis. Processed radiological images were repositioned in each of the three planes of space using DataViewer (version 1.5.0, 64-bit; SkyScan), and areas outside the field of radiological images were removed. Sizes were reduced to make mathematical analysis faster. The resulting new data series was loaded onto CT analyzer (version 1.13.5.1; SkyScan), and the first and last sections in the sagittal plane sections were established. Considering the number of sections in the selected cross section range, the linear function of distance was measured between the following locations, using the program in ten sections: mesial cementoenamel junction to mesial root apex, mesial cementoenamel junction to mesial crestal bone, furcation roof to furcation root apex, furcation roof to furcation crestal bone, distal cementoenamel junction to distal root apex, and distal cementoenamel junction to distal crestal bone (Figure 2A-F). An average of ten measurements was taken from each specimen by a blinded and calibrated examiner.

\section{Statistical analysis}

Statistical analysis was performed using SPSS Statistics (version 22.0; IBM Corporation, Armonk, NY, USA). The appropriateness of the normal distribution of the parameters was assessed by the Kolmogorov-Smirnov test. The differences between groups were tested. A oneway analysis of variance was performed for the parameters showing a normal distribution. Tukey's honestly significant difference test was used to detect which group caused the difference. Between-group differences were tested using the Kruskal-Wallis $H$ test for parameters showing a nonnormal distribution, and the Mann-Whitney $U$-test was 

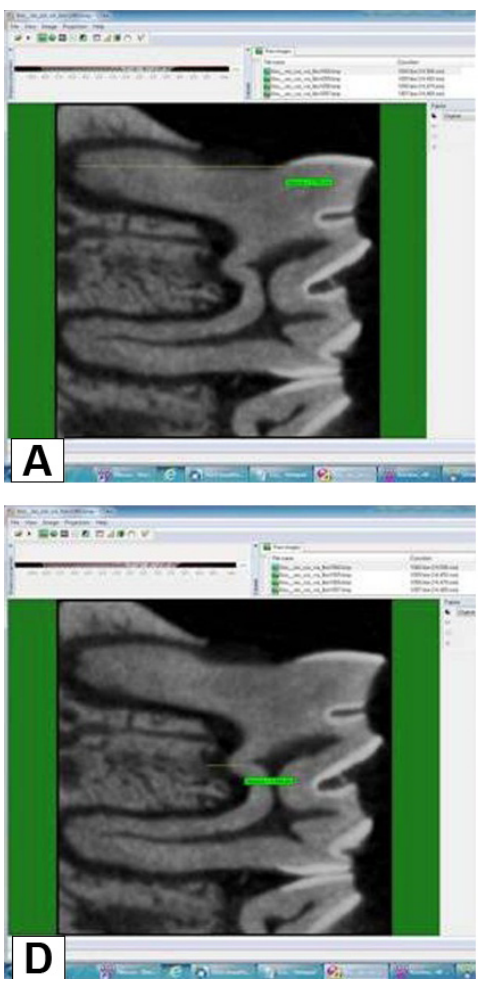
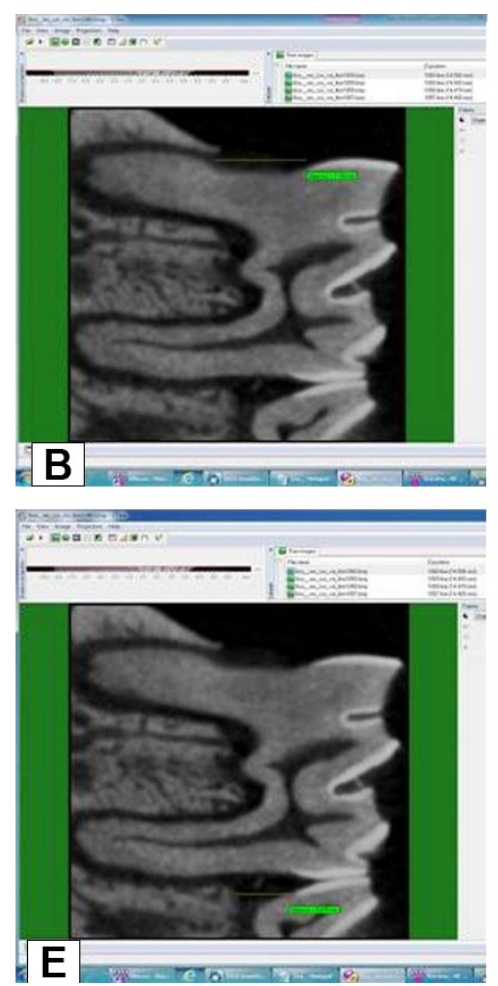
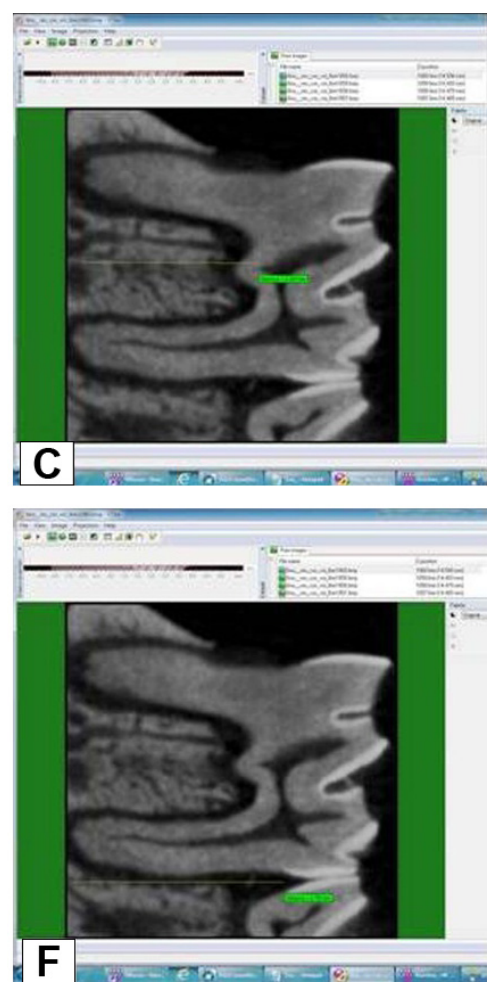

Figure 2 Measurement of the distances between (A) MMCJ and MRA, (B) MMCJ and MRA, (C) FR and FRCB, (D) FR and FRRA, (E) DMCJ and DCB, (F) DMCJ and DRA. Abbreviations: DCB, distal crestal bone; DMC], distal cementoenamel junction; DRA, distal root apex; FR, furcation roof; FRCB, furcation crestal bone; FRRA, furcation root apex; MCB, mesial crestal bone; MMCJ, mesial cementoenamel junction; MRA, mesial root apex.

used to detect which group caused the difference. Results yielding $P$-values $<0.05$ were considered statistically significant.

\section{Results}

\section{Western blot results}

The RANK level in the control group was significantly lower than that in the periodontitis, ASI I, and ASI II groups $(P<0.05)$. The RANK level in the ASI I group was significantly higher than that in the control and ASI II groups, and the RANK level in the periodontitis group was significantly higher than that in the ASI II group $(P<0.05)$. No statistically significant differences were detected for RANK levels between the ASI I and ASI II groups and between the periodontitis and ASI I groups $(P>0.05)$ (Table 1) (Table 2; Figure $3 \mathrm{~A}-\mathrm{D})$. The RANKL level in the periodontitis group was significantly higher than that in the control, ASI I, and ASI II groups $(P<0.05)$. The RANKL level in the control group was significantly lower than that in the ASI I and ASI II groups $(P<0.05)$. No statistically significant differences were found between the ASI I and ASI II groups for RANKL levels $(P>0.05)$ (Table 2; Figure 3A-D).

Table 2 Western blot findings of the groups

\begin{tabular}{|c|c|c|c|c|c|}
\hline & Control & Periodontitis & ASI I & ASI II & $P$-value \\
\hline & Mean \pm SD & Mean \pm SD & Mean \pm SD & Mean \pm SD & \\
\hline IL-I $\beta$ & $100.00 \pm 5.24$ & $189.82 \pm 1.84^{\mathrm{a}}$ & $142.5 \pm 2.53^{\mathrm{a}, \mathrm{b}}$ & $111.24 \pm 2.35^{a-c}$ & $0.016 *$ \\
\hline MMP-8 & $100.00 \pm 2.72$ & $208.72 \pm 11.14^{\mathrm{a}}$ & $166.79 \pm 7.86^{\mathrm{a}, \mathrm{b}}$ & $|50.256 \pm| \mid .60^{a, b}$ & $0.019 *$ \\
\hline RANK & $100.00 \pm 4.31$ & $202.18 \pm 2.83^{\mathrm{a}}$ & $189.27 \pm 5.30^{\mathrm{a}, \mathrm{b}}$ & $|74.3| \pm 9.82^{\mathrm{a}, \mathrm{b}}$ & $0.023^{*}$ \\
\hline RANKL & $100.00 \pm 8.06$ & $167.06 \pm 10.72^{\mathrm{a}}$ & $|50.1| \pm 6.34^{\mathrm{a}, \mathrm{b}}$ & $138.35 \pm 13.60^{\mathrm{a}, \mathrm{b}}$ & $0.022 *$ \\
\hline OPG & $100.00 \pm 2.30$ & $47.25 \pm 2.33^{\mathrm{a}}$ & $72.87 \pm 4.67^{\mathrm{a}, \mathrm{b}}$ & $91.13 \pm 3.04^{\mathrm{a}-\mathrm{c}}$ & $0.016 *$ \\
\hline MPO & $100.00 \pm 6.90$ & $228.86 \pm 1.13^{a}$ & $180 \pm 2.97^{a, b}$ & $159.59 \pm 13.09^{a-c}$ & $0.016^{*}$ \\
\hline
\end{tabular}

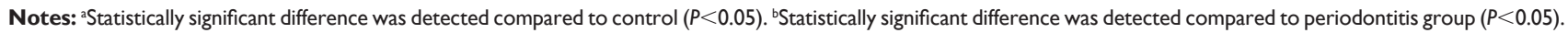
'Statistically significant difference was detected compared to ASI I group $(P<0.05)$ * *P<0.05. ASI I group: $1.81 \mathrm{~g} / \mathrm{kg}$ ASI complex; ASI II group: $3.62 \mathrm{~g} / \mathrm{kg}$ ASI complex.

Abbreviations: ASI, arginine silicate inositol; IL, interleukin; MMP, matrix metalloproteinase; MPO, myeloperoxidase; OPG, osteoprotegerin; RANK, receptor activator of nuclear factor-KB; RANKL, RANK ligand. 


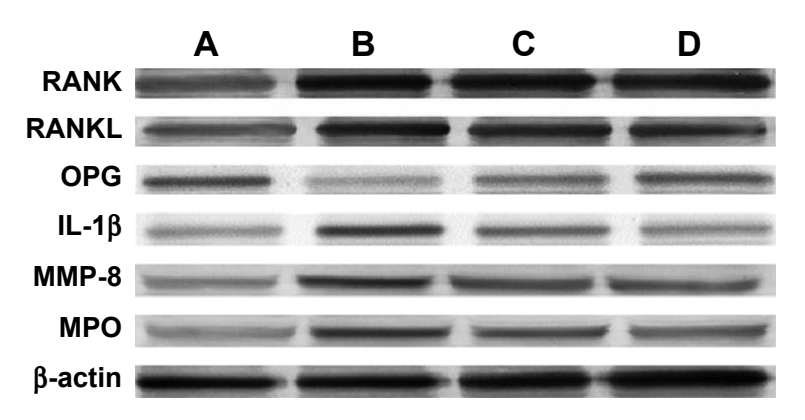

Figure 3 (A) Control, (B) Periodontitis, (C) ASI I and (D) ASI II.

Abbreviations: $\mathrm{ASI}$, arginine silicate inositol; IL, interleukin; MMP, matrix metalloproteinase; MPO, myeloperoxidase; OPG, osteoprotegerin; RANK, receptor activator of nuclear factor- $\mathrm{KB}$; RANKL, RANK ligand.

The OPG level in the periodontitis group was significantly lower than that in the control, ASI I, and ASI II groups $(P<0.05)$. The OPG level in the ASI I group was significantly lower than that in the control and ASI II groups $(P<0.05)$. The OPG level in the ASI II group was significantly lower than that in the control group $(P<0.05)$ (Table 2; Figure 3A-D).

Significantly higher tissue level of IL-1 $\beta$ was found in the ligature-induced periodontitis group in comparison to control animals, independently of experimental periods $(P<0.05)$. However, significantly lower concentrations of IL-1 $\beta$ were found in the ASI-treated groups (ligature-induced periodontitis and ASI) in comparison to positive control animals, independently of experimental periods $(P<0.05$; Table 2, Figure 3A-D).

A significant increase in MMP-8 and MPO levels, an index of tissue granulocytic infiltration, was found in the periodontitis group when compared with the control group. A significant decrease in MMP-8 and MPO levels was found in the ASI groups when compared with the positive and control groups $(P<0.05$; Table 2, Figure 3A-D).

\section{Radiological results}

The mesial bone loss ratio in the control group was significantly lower than that in the periodontitis, ASI I, and
ASI II groups $(P<0.05)$. The mesial bone loss ratio in the periodontitis group was significantly higher than that in the ASI I and ASI II groups $(P<0.05)$. No statistically significant difference was detected between the ASI I and ASI II groups for the ratio of mesial bone loss $(P>0.05)$ (Table 3; Figure 4A-D). The furcation bone loss ratio in the control group was significantly lower than that in the periodontitis, ASI I, and ASI II groups $(P<0.05)$. The furcation bone loss ratio of the periodontitis group was significantly higher than that in the ASI I and ASI II groups $(P<0.05)$. No statistically significant difference was detected between the ASI I and ASI II groups for the ratio of furcation bone loss $(P>0.05)$ (Table 3; Figure 4A-D). No statistically significant difference was detected between the ASI I and ASI II groups for the ratio of distal bone loss $(P>0.05)$ (Table 3; Figure 4A-D).

\section{Discussion}

Although research on new agents for host modulation therapy to treat periodontal diseases is ongoing, the FDA has only approved subantimicrobial-dose tetracycline and enamel matrix protein for host modulatory therapy. ${ }^{5,7-10}$ Research has demonstrated that arginine and silicon increase immune function and osteoblastic activity, as well as wound healing in bone and connective tissues. ${ }^{11-15}$ Based on these data, this study aimed to investigate the effects of ASI complex supplementation on periodontal tissues during periodontitis formation.

The ligature-induced periodontitis model was used in accordance with the literature ${ }^{30-32}$ The tissue destruction parameters in the periodontitis group were higher than those in the control group, which is in line with previously reported studies that suggest ligature-induced periodontitis. ${ }^{32-35}$ Toker et al, ${ }^{31,32}$ in their study inducing periodontitis by binding silk sutures around rat molar teeth, reported that plaque and bacteria accumulation increased in the region where silk sutures contacted the tissue.

Two components of the product used in this study, arginine and silicon, have been shown to increase osteogenesis. ${ }^{24,28,29}$ Arginine deficiency may be involved in osteoporosis,

Table 3 MCT findings of the groups

\begin{tabular}{|c|c|c|c|c|c|}
\hline & Control & Periodontitis & ASI I & ASI II & $P$-value \\
\hline & $\overline{\text { Mean } \pm \text { SD }}$ & Mean \pm SD & $\overline{\text { Mean } \pm \text { SD }}$ & $\overline{\text { Mean } \pm \text { SD }}$ & \\
\hline MMCJ-MCB/MMCJ-MRA & $0.28 \pm 0.05$ & $0.54 \pm 0.04^{\mathrm{a}}$ & $0.49 \pm 0.10^{a, b}$ & $0.50 \pm 0.10^{\mathrm{a}, \mathrm{b}}$ & $0.00 I^{* *}$ \\
\hline FR-FRCB/FR-FRRA & $0.07 \pm 0.02$ & $0.26 \pm 0.05^{\mathrm{a}}$ & $0.21 \pm 0.04^{\mathrm{a}, \mathrm{b}}$ & $0.22 \pm 0.05^{\mathrm{a}, \mathrm{b}}$ & $0.00 I^{* *}$ \\
\hline DMCJ-DCB/DMCJ-DRA & $0.32 \pm 0.12$ & $0.42 \pm 0.09$ & $0.4 I \pm 0.12$ & $0.42 \pm 0.08$ & 0.190 \\
\hline
\end{tabular}

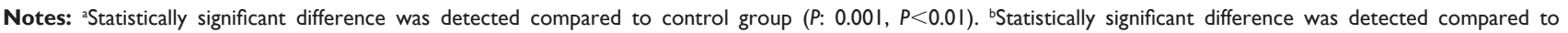
periodontitis group (P: $0.00 \mathrm{I}, P<0.0 \mathrm{I})$. $* * P<0.0 \mathrm{I}$. ASI I group: $1.8 \mathrm{I} \mathrm{g} / \mathrm{kg}$ ASI complex; ASI II group: $3.62 \mathrm{~g} / \mathrm{kg}$ ASI complex.

Abbreviations: ASI, arginine silicate inositol; DCB, distal crestal bone; DMCJ, distal cementoenamel junction; DRA, distal root apex; FR, furcation roof; FRCB, furcation crestal bone; FRRA, furcation root apex; MCT, micro-computed tomography; MCB, mesial crestal bone; MMC], mesial cementoenamel junction; MRA, mesial root apex. 

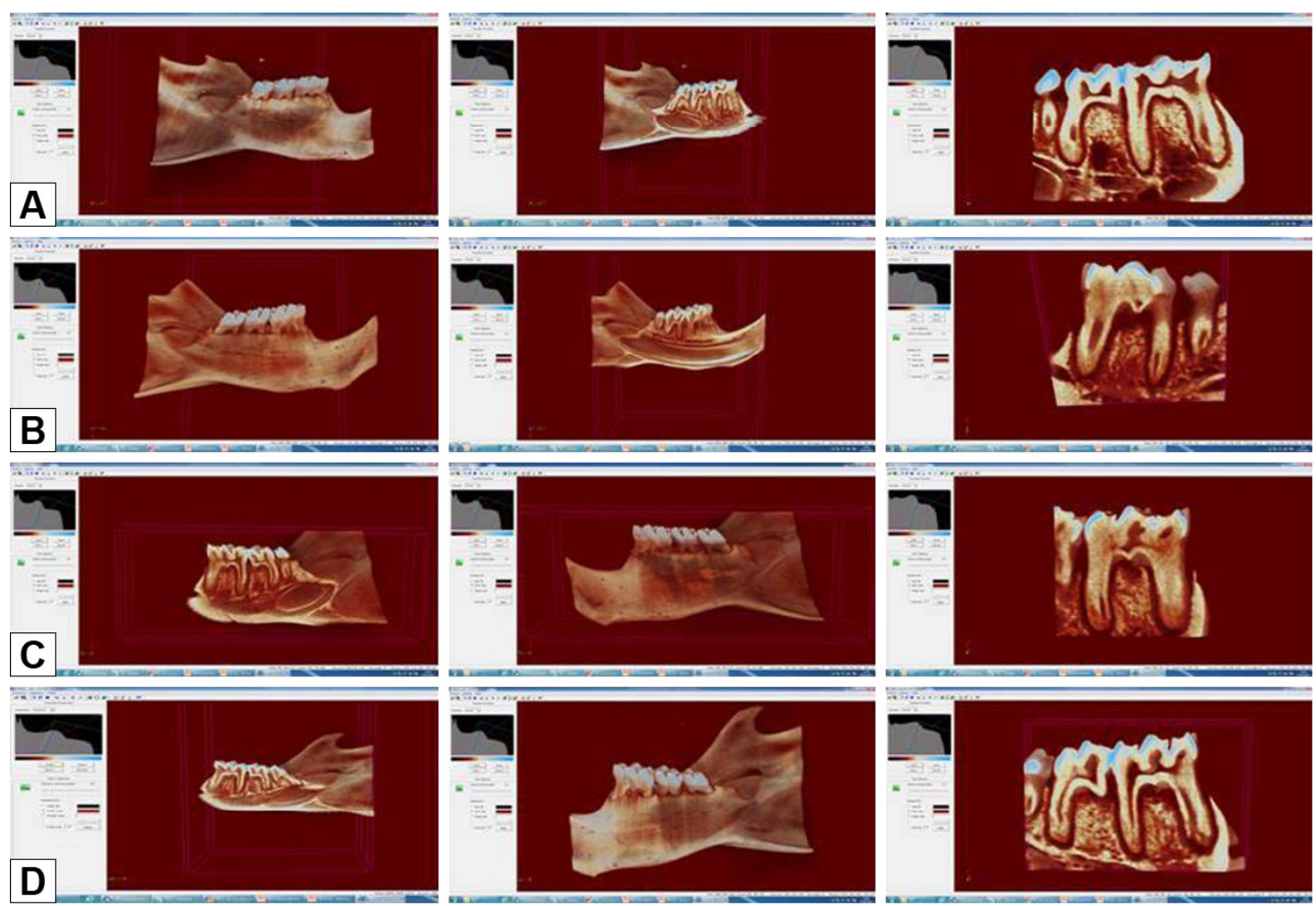

Figure 4 Radiologic images of the groups.

Notes: (A) Control group; rats were fed a basal diet for 8 weeks with no ligature placement (B) periodontitis group; rats were fed a basal diet for 8 weeks prior to II-day ligature placement (C) ASI I group; rats were fed a supplementation of I.8I g/kg of ASI complex for 8 weeks prior to II-day ligature placement (D) ASI II group; rats were fed a supplementation of $3.62 \mathrm{~g} / \mathrm{kg}$ of ASI complex for 8 weeks prior to II-day ligature placement.

Abbreviation: ASI, arginine silicate inositol.

fractures, and bone defects. ${ }^{21}$ Arginine is involved in the synthesis of growth hormone, IGF, as well as polyamines and L-proline, which act as substrates for collagen synthesis. ${ }^{21-23}$ As the precursor of NO, which has been shown to prevent corticosteroid-induced bone loss in mature rats, ${ }^{36}$ arginine is an essential amino acid and is necessary for the antimicrobial activity of polymorphonuclear leukocytes (PMNLs), macrophages, and mononuclear cells. ${ }^{37}$ Moffat et $\mathrm{a}^{38}$ found in an in vitro study that arginine had an effect on NO synthase (NOS) and also caused an increase in phagocytic effects of PMNLs against Staphylococcus aureus. When leukocytes are stimulated with lipopolysaccharides, they produce inducible NOS from NO. This mechanism is an important part of the innate and adaptive immune systems. The presence of inducible NOS in macrophages and neutrophils plays an essential role in the antimicrobial function of these cells against fungi, viruses, parasites, bacteria, malignant cells, and intracellular protozoa. ${ }^{39}$ Torricelli et $\mathrm{al}^{40}$ reported that arginine in human osteoblasts markedly increased certain parameters, called bone formation markers, such as alkaline phosphatase, NO, type I collagen, and IGF. These markers increased the synthesis of bone matrix, acting at the cellular level in bone tissue. Torricelli et $\mathrm{al}^{40}$ also reported that the effects of arginine on bone tissue were directly related to the effect on the cell proliferation mechanism. In the same study, IL-6 production was determined to be lower in osteoblasts exposed to arginine. ${ }^{40}$

Silicon has been implicated as an important component in bone formation, and its deficiency negatively influences skeletal development. ${ }^{41}$ The primary effect of silicon on bone and cartilage is thought to be through matrix synthesis, although it also has a significant influence on calcification. ${ }^{42,43}$ Silicon supplementation inhibits bone resorption and increases trabecular bone volume and bone mineral density in postmenopausal women with osteoporosis. ${ }^{42,43}$ Although limited in vivo research has been done, silicon increases osteoblastic activity and decreases osteoclastic activity in vitro. ${ }^{13,14,44}$ Schroder et $\mathrm{al}^{45}$ and Wiens et $\mathrm{al}^{46}$ reported that the OPG produced increased osteoblast-like cells exposed to silicate, but no changes occurred in the production of the receptor activator of RANKL. These researchers stated that the increased OPG emission suppressed RANKL activity and consequently increased osteoclastogenesis. Additionally, Sahin et al ${ }^{13}$ and Onderci et $\mathrm{al}^{14}$ examined the effects of ASI complex on bone tissue in a study on poultry fed a diet supplemented with either $500 \mathrm{mg} / \mathrm{kg}$ or $1,000 \mathrm{mg} / \mathrm{kg}$ ASI. In these studies, increased levels of bone mineral density, calcium, and phosphorus 
were seen in the tibia, and increased levels of osteocalcin and alkaline phosphatase were found in the serum, depending on dose in both of the experimental groups compared to the controls. The results of this study, which indicate that the ASI complex could be effective in reducing tissue destruction parameters, confirm these previous results.

Periodontitis can initiate tissue and alveolar bone destruction through the activation of several proinflammatory cytokines, including IL-1 $\beta .{ }^{47}$ Cytokines might have a direct influence on bone remodeling, as IL-1 seems to stimulate osteoblasts to produce a set of cytokines (IL-6 and tumor necrosis factor [TNF]- $\alpha$ ) that are capable of directly influencing bone resorption processes. ${ }^{48}$ These cytokines play key roles in the breakdown of periodontal tissue through collagenolytic enzymes such as MMPs (a family of related zinc-containing proteinases), which can degrade most of the extracellular matrix. ${ }^{49}$ Additionally, the balance between bone resorption and bone formation is regulated by the production of RANKL and its decoy receptor, OPG, both essential molecules for osteoclast differentiation supported by osteoblasts. ${ }^{49,50}$ This study demonstrated that the administration of ASI significantly reduced the levels of bone-related molecules (RANK and RANKL), neutrophil infiltration, and cytokine production in gingival tissue (IL-1 $\beta$ ), as well as collagenolytic enzymes (MMP8), in the experimental periodontitis-induced rats. However, ASI supplementation increased OPG levels in the experimental periodontitisinduced rats. These results are compatible with results from other studies reporting that the compounds of ASI were effective on important mechanisms of the immune system, such as lymphocyte growth and the excessive release of proinflammatory cytokines. ${ }^{13,16}$ Similar to our results, Sahin et $\mathrm{al}^{13}$ reported that dietary ASI supplementation decreased serum concentrations of TNF- $\alpha$ and $\mathrm{C}$-reactive protein in stressed animals.

Although this study showed that dietary ASI complex was associated with decreased levels of indicators of periodontal tissue destruction, the effects of arginine and silicon were not evaluated separately. This limitation must be considered when evaluating the findings. It is difficult to examine the difference between the synergistic interaction formed by the distinctive impact levels of the individual materials and the combined use of the same materials.

\section{Conclusion}

Although this study has limitations that must be considered, it appears that ASI complex supplementation could have decreased periodontal tissue destruction in the rat experimental ligature-induced periodontitis model. Further studies on the effects of ASI complex supplementation on periodontal tissue destruction are needed, as well as research on the effects of new agents on the mechanisms of tissue destruction.

\section{Acknowledgments}

We thank Nurhan Sahin and Cemal Orhan for their collaboration in our experiments. This work was supported by the Scientific Research Project Fund of Inonu University under project number 2013/88 and the Turkish Academy of Sciences (to KS).

\section{Disclosure}

The authors report no conflicts of interest in this work.

\section{References}

1. Gumus P, Nizam N, Nalbantsoy A, Ozcaka O, Buduneli N. Saliva, serum levels of pentraxin-3 and interleukin-1beta in generalised aggressive or chronic periodontitis. J Periodontol. 2014;85(3):40-46.

2. Salvi GE, Lang NP. Host response modulation in the management of periodontal diseases. J Clin Periodontol. 2005;32(suppl 6):108-129.

3. Hasturk H, Kantarci A, Van Dyke TE. Oral inflammatory diseases and systemic inflammation: role of the macrophage. Front Immunol. 2012; 3(118):1-17.

4. Yucel-Lindberg T, Bage T. Inflammatory mediators in the pathogenesis of periodontitis. Expert Rev Mol Med. 2013;15:1-7.

5. Elavarasu S, Sekar S, Murugan T. Host modulation by therapeutic agents. J Pharm Bioallied Sci. 2012;4(suppl 2):256-259.

6. Ustun K, Erciyas K, Kisacik B, et al. Host modulation in rheumatoid arthritis patients with TNF blockers significantly decreases biochemical parameters in periodontitis. Inflammation. 2013;36(5):1171-1177.

7. Tariq M, Iqbal Z, Ali J, et al. Treatment modalities and evaluation models for periodontitis. Int J Pharm Investig. 2012;2(3):106-122.

8. Kara A, Akman S, Ozkanlar S, et al. Immune modulatory and antioxidant effects of melatonin in experimental periodontitis in rats. Free Radic Biol Med. 2013;55:21-26.

9. Akman S, Canakci V, Kara A, Tozoglu U, Arabaci T, Dagsuyu IM. Therapeutic effects of alpha lipoic acid and vitamin $\mathrm{C}$ on alveolar bone resorption after experimental periodontitis in rats: a biochemical, histochemical, and stereologic study. J Periodontol. 2013;84(5):666-674.

10. Hakki SS, Foster BL, Nagatomo KJ, et al. Bone morphogenetic protein-7 enhances cementoblast function in vitro. J Periodontol. 2010;81(11): 1663-1674.

11. Proctor SD, Kelly SE, Russell JC. A novel complex of argininesilicate improves micro- and macrovascular function and inhibits glomerular sclerosis in insulin-resistant JCR:LA-cp rats. Diabetologia. 2005;48(9):1925-1932.

12. Proctor SD, Kelly SE, Vine DF, Russell JC. Metabolic effects of a novel silicate inositol complex of the nitric oxide precursor arginine in the obese insulin-resistant JCR:LA-cp rat. Metabolism. 2007;56(10): $1318-1325$.

13. Sahin K, Onderci M, Sahin N, et al. Dietary arginine silicate inositol complex improves bone mineralization in quail. Poult Sci. 2006;85(3): 486-492.

14. Onderci M, Sahin N, Sahin K, et al. Dietary arginine silicate inositol complex during the late laying period of quail at different environmental temperatures. Br Poult Sci. 2006;47(2):209-215.

15. Russell JC. A novel complex of arginine - silicate improves micro- and macrovascular function and inhibits glomerular sclerosis in insulinresistant JCR: LA-Cp rats. Diabetologia. 2005;48(9):1925-1932.

16. Adams MR, Forsyth CJ, Jessup W, Robinson J, Celermajer DS. Oral L-arginine inhibits platelet aggregation but does not enhance endothelium dependent dilation in healthy young men. J Am Coll Cardiol. 1995;26(4):1054-1061. 
17. Lerman A, Burnett JC Jr, Higano ST, Mckinley LJ, Holmes DR Jr. Long term L-arginine supplementation improves small-vessel coronary endothelial function in humans. Circulation. 1998;97(21):2123-2128.

18. Levine J. Controlled trials of inositol in psychiatry. Eur Neuropsychopharmacol. 1997;7(2):147-155.

19. Van Dyck K, Van Cauwenbergh R, Robberecht H, Deelstra H. Bioavailability of silicon from food and food supplements. Fresenius J Anal Chem. 1999;363:541-544.

20. Seaborn CD, Nielsen FH. Silicon deprivation decreases collagen formation in wounds and bone, and ornithine transaminase enzyme activity in liver. Biol Trace Elem Res. 2002;89(3):251-261.

21. Chevalley T, Rizzoli R, Manen D, Caverzasio J, Bonjour JP. Arginine increases insulin-like growth factor-I production and collagen synthesis in osteoblast-like cells. Bone. 1998;23(2):103-109.

22. Trippel SB. Potential role of insulin-like growth factors in fracture healing. Clin Orthop. 1998;355:301-313.

23. Colao A, Di Somma C, Pivonello R, et al. Bone loss is correlated to the severity of growth hormone deficiency in adult patients with hypopituitarism. J Clin Endocrinol Metab. 1999;84(6):1919-1924.

24. Fiore CE, Pennisi P, Cutuli VM, Prato A, Messina R, Clementi G. L-arginine prevents bone loss and bone collagen breakdown in cyclosporin A-treated rats. Eur J Pharmacol. 2000;408(3):323-326.

25. Clementi G, Fiore CE, Margano NG. Role of soy diet and L-arginine in cyclosporine A-induced osteopenia in rats. Pharmacol Toxicol. 2001; 88(1):16-19.

26. Carlisle EM. Silicon as an essential element for the chick. Science. 1972;178(4061):619-621.

27. Schwarz K, Milne DB. Growth promoting effects of silicon in rats. Nature. 1972;239(5371):333-334.

28. Carlisle EM. In vivo requirement for silicon in articular cartilage and connective tissue formation in the chick. J Nutr. 1976;106(4):478-484.

29. Carlisle EM. Silicon: a possible factor in bone calcification. Science. 1970;167(3916):279-280.

30. Sakallioglu EE, Ayas B, Lutfioglu M, Keles GC, Acikgoz G, Firatli E. Gingival levels of monocyte chemoattractant protein-1 (MCP-1) in diabetes mellitus and periodontitis: an experimental study in rats. Clin Oral Investig. 2008;12(1):83-89.

31. Toker H, Ozan F, Ozer H, Ozdemir H, Eren K, Yeler H. A morphometric and histopathologic evaluation of the effects of propolis on alveolar bone loss in experimental periodontitis in rats. $J$ Periodontol. 2008;79(6):1089-1094.

32. Toker H, Ozdemir H, Eren K, Ozer H, Sahin G. N-acetylcysteine, a thiol antioxidant, decreases alveolar bone loss in experimental periodontitis in rats. J Periodontol. 2009;80(4):672-678.

33. Wei PF, Ho KY, Ho YP, Wu YM, Yang YH, Tsai CC. The investigation of glutathione peroxidase, lactoferrin, myeloperoxidase and interleukin1beta in gingival crevicular fluid: implications for oxidative stress in human periodontal diseases. J Periodontal Res. 2004;39(5):287-293.

34. Bostanci N, Ilgenli T, Emingil G, et al. Gingival crevicular fluid levels of RANKL and OPG in periodontal diseases: implications of their relative ratio. J Clin Periodontol. 2007;34(5):370-376.
35. Gomes DA, Pires JR, Zuza EP, et al. Myeloperoxidase as inflammatory marker of periodontal disease: experimental study in rats. Immunol Invest. 2009;38(2):117-122.

36. Wimalawansa SJ, Chapa MT, Yallampalli C, Zhang R, Simmons DJ. Prevention of corticosteroid-induced bone loss with nitric oxide donor nitroglycerin in male rats. Bone. 1997;21(3):275-280.

37. Popovic PJ, Zeh HJ 3rd, Ochoa JB. Arginine and immunity. J Nutr. 2007;137(6 suppl 2):1681-1686.

38. Moffat FL Jr, Han T, Li ZM, et al. Supplemental L-arginine HCl augments bacterial phagocytosis in human polymorphonuclear leukocytes. J Cell Physiol. 1996;168(1):26-33.

39. Li P, Yin Y, Li D, Kim SW, Wu G. Amino acids and immune function. Br J Nutr. 2007;98(2):237-252.

40. Torricelli P, Fini M, Giavaresi G, et al. L-arginine and L-lysine stimulation on cultured human osteoblasts. Biomed Pharmacother. 2002; 56(10):492-497.

41. Kim MH, Kim EJ, Jung JY, Choi MK. Effect of water-soluble silicon supplementation on bone status and balance of calcium and magnesium in male mice. Biol Trace Elem Res. 2014;158(2):238-242.

42. Seaborn CD, Nielsen FH. Effects of germanium and silicon on bone mineralization. Biol Trace Elem Res. 1994;42(2):151-164.

43. Eisinger J, Clairet D. Effects of silicon, fluoride, etidronate and magnesium on bone mineral density: a retrospective study. Magnes Res. 1993;6(3):247-249.

44. Schutze N, Oursler MJ, Nolan J, Riggs BL, Spelsberg TC. Zeolite A inhibits osteoclast-mediated bone resorption in vitro. $J$ Cell Biochem. 1995;58(1):39-46.

45. Schroder HC, Wang XH, Wiens M, et al. Silicate modulates the crosstalk between osteoblasts (SaOS-2) and osteoclasts (RAW 264.7 cells): inhibition of osteoclast growth and differentiation. $J$ Cell Biochem. 2012;113(10):3197-3206

46. Wiens M, Wang X, Schroder HC, et al. The role of biosilica in the osteoprotegerin/RANKL ratio in human osteoblast-like cells. Biomaterials. 2010;31(30):7716-7725.

47. Napimoga MH, Benatti BB, Lima FO, et al. Cannabidiol decreases bone resorption by inhibiting RANK/RANKL expression and proinflammatory cytokines during experimental periodontitis in rats. Int Immunopharmacol. 2009;9(2):216-222.

48. Suda T, Takahashi N, Udagawa N, Jimi E, Gillespie MT, Martin TJ. Modulation of osteoclast differentiation and function by the new members of the tumor necrosis factor receptor and ligand families. Endocr Rev. 1999;20(3):345-357

49. Araújo AA, Varela H, Brito GA, et al. Azilsartan increases levels of IL-10, down-regulates MMP-2, MMP-9, RANKL/RANK, Cathepsin $\mathrm{K}$ and up-regulates OPG in an experimental periodontitis model. PLoS One. 2014;9(5):e96750.

50. Guimarães MV, Melo IM, Adriano Araújo VM, et al. Dry extract of Matricaria recutita L. (chamomile) prevents ligature-induced alveolar bone resorption in rats via inhibition of tumor necrosis factor- $\alpha$ and interleukin-1 $\beta$. J Periodontol. 2016;87(6):706-715.
Drug Design, Development and Therapy

\section{Publish your work in this journal}

Drug Design, Development and Therapy is an international, peerreviewed open-access journal that spans the spectrum of drug design and development through to clinical applications. Clinical outcomes, patient safety, and programs for the development and effective, safe, and sustained use of medicines are the features of the journal, which

\section{Dovepress}

has also been accepted for indexing on PubMed Central. The manuscript management system is completely online and includes a very quick and fair peer-review system, which is all easy to use. Visit http://www.dovepress.com/testimonials.php to read real quotes from published authors. 